\title{
Does the grey mouse lemur use agonistic vocalisations to recognise kin?
}

\author{
Sharon E. Kessler ${ }^{1,2,3,5}$, Ute Radespiel ${ }^{3}$, Alida I. F. Hasiniaina ${ }^{3,4}$, Leanne T. Nash $^{1}$, Elke Zimmermann $^{3}$ \\ ${ }^{1}$ Durham University, Department of Anthropology,_South Rd, Durham DH1 3LE, UK. \\ ${ }^{2}$ Arizona State University, School of Human Evolution and Social Change, Box 872402, Tempe, AZ 85287-2402 \\ U.S.A. \\ ${ }^{3}$ University of Veterinary Medicine Hannover, Institute of Zoology, Bünteweg 17, 30559 Hannover, Germany. \\ ${ }^{4}$ Faculté des Sciences, Université de Mahajanga, BP 652, Mahajanga, Madagascar \\ ${ }^{5}$ E-mail: Sharon.e.Kessler@durham.ac.uk
}

Keywords: Playback experiment, kin recognition, solitary forager, ancestral primate, Microcebus murinus, Madagascar

\begin{abstract}
Frequent kin-biased coalitionary behaviour is a hallmark of mammalian social complexity. Furthermore, selection to understand complex social dynamics is believed to underlie the co-evolution of social complexity and large brains. Vocalisations have been shown to be an important mechanism with which large-brained mammals living in complex social groups recognise and recruit kin for coalitionary support during agonistic conflicts. We test whether kin recognition via agonistic calls occurs in a small-brained solitary foraging primate living in a dispersed social network, the grey mouse lemur (Microcebus murinus, Miller JF, 1777). As mouse lemurs are frequent models for ancestral solitary foraging mammals, this study examines whether kin recognition via agonistic calls could be the foundation from which more complex, kin-based coalitionary behaviour evolved. We test whether female wild mouse lemurs in Ankarafantsika National Park, Madagascar, react differently to agonistic calls from kin and nonkin and to calls from familiar and unfamiliar individuals during playback experiments. Subjects showed no significant differences in reactions to the different stimuli; thus they did not react differently based upon kinship or familiarity. Results suggest that this solitary foraging species does not use agonistic calls to recognise kin and monitor agonistic interactions involving kin, unlike several species of Old World monkeys and hyenas. Thus, kin recognition via agonistic calls may have evolved independently in these lineages in parallel with greater social complexity and frequent coalitionary behaviour.
\end{abstract}

\section{Contents}

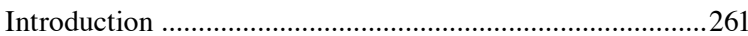

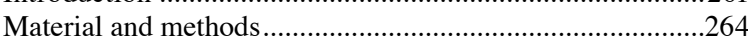

Field site and trapping methodology ................................264

Recording vocalisations.................................................265

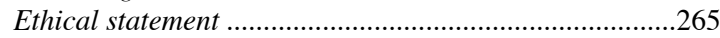

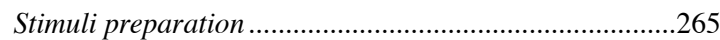

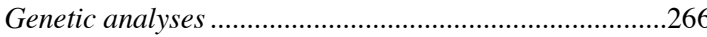

Classification of kin, neighbour, cage-mate and

stranger dyads .266

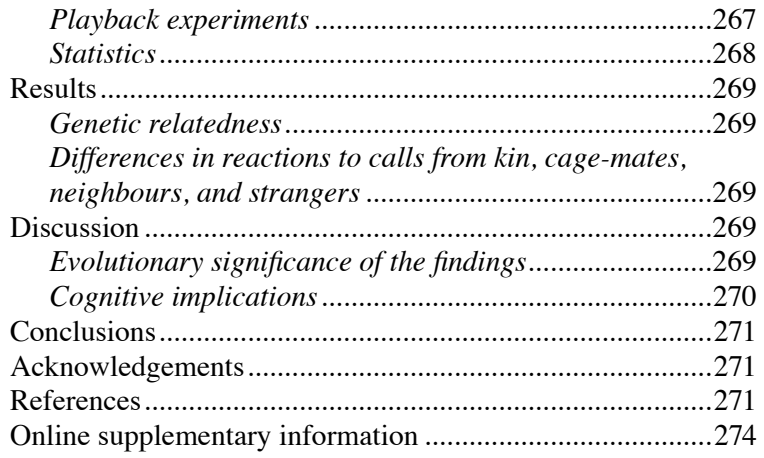

\section{Introduction}

A key element of mammalian social complexity is kin-biased coalitionary behaviour. The selective pressure to monitor the multiple, complex dyadic relationships occurring in social groups is argued to underlie the co-evolution of social complexity and large brains (Chapais, 1995; Dunbar, 1998; de Waal and Tyack, 2003; Dunbar, 2003; Silk, 2007). Among the most difficult to monitor are coalitionary behaviours in which the interactions within one dyad have implications for a third individual, i.e., third party interventions, coalitionary aggression (in the sense of Gompper et al., 1997) (Dunbar, 1998). These agonistic interactions may lead to costly injuries or even a decrease in inclusive fitness (Hamilton, 1964) when serious harm to kin is not prevented i.e. lethal aggression (Gros-Louis et al., 2003; Talebi et al., 2009; Gilby et al., 2013). Furthermore, agonistic interactions are fast-paced and may occur out of sight due to dense foliage, distance, or darkness, making monitoring them all the more difficult. Thus, kin selection (Hamilton, 1964) should select for agonistic 
signals which will effectively recruit aid from kin under these circumstances.

Among mammals, matrilineal kin are expected to be more widely recognised due to the obligate relationship between infants and their mother during nursing (Rendall, 2004) and are thus more probable coalition partners than paternal kin (but see Smith et al., 2003; Widdig et al., 2006). The extended period of infant care provided by mammalian mothers ensures the opportunity for mothers, current offspring, and siblings to become highly familiar with each other, and thus facilitates kin recognition via the proximate mechanism of familiarity (Rendall, 2004). While theory suggests that direct genetic detection, in which individuals recognise genetic relatedness in the absence of any other cues (Rendall, 2004), would be more accurate, decades of study have amassed strong evidence (Chapais and Berman, 2004) to suggest that familiarity is the major proximate mechanism enabling primates to bias their behaviour in favour of matrilineal kin, i.e., matrilineal kin selection. In order to clearly distinguish between direct genetic detection and familiarity, we refer to kin recognition via the proximate mechanism of familiarity.

Vocalisations are a likely medium for the recruitment of kin for two reasons. First, they have the advantage that they may convey information to conspecifics that are out of sight. Second, they are a widely used cue for matrilineal kin recognition among both large and small-brained mammals i.e. primates (Cheney and Seyfarth, 1980; Rendall et al., 1996; Nunn, 2000; Seyfarth and Cheney, 2003; Rendall, 2004; Rendall et al., 2009), hyenas (Holekamp et al., 1999), elephants (McComb et al., 2000, 2003), pinnipeds (Insley et al., 2003), goats (Briefer and McElligott, 2011; Briefer et al., 2012), bats (Balcombe, 1990; Knoernschild and Von Helversen, 2008). This widespread recognition of maternal kin via vocalisations suggests that agonistic calls may also be sufficient for kin recruitment, as they are used for kin recognition. And, indeed, multiple large-brained, socially complex mammals known to engage in high rates of coalitionary behaviour with maternal kin (Chapais, 1995; Silk, 2002, 2007; Silk et al., 2004) have been shown to recognise the agonistic calls of their kin and, for some species, kin relationships among conspecific dyads as well (Cheney and Seyfarth, 1980, 1999; Wittig et al., 2007; Fugate et al., 2008). Baboon females react more strongly to threat grunts from kin of a previous conflict partner than to kin of a female with whom they just had an affiliative interaction (Wittig et al., 2007). Moreover,

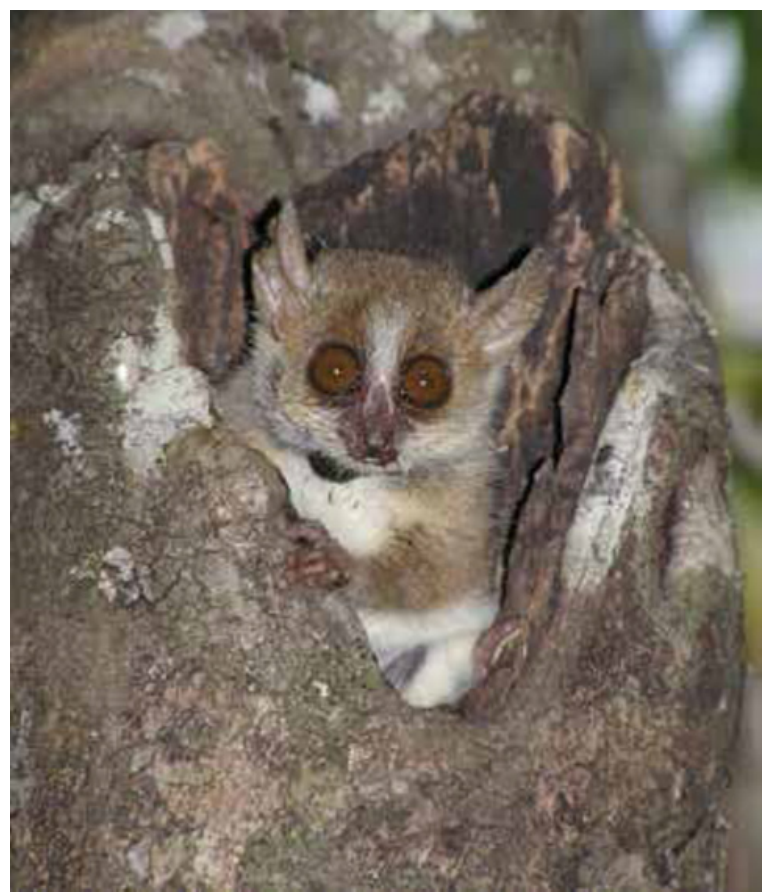

Figure 1. A photo of a grey mouse lemur in a tree hole wearing a radio-collar. Photo: S. E. Kessler

after hearing calls mimicking an agonistic encounter between female kin and a non-kin group-mate, a female listener is more likely to behave aggressively towards the kin of the female that was in conflict with her kin (Cheney and Seyfarth, 1999). Both vervet and spotted hyena mothers respond more strongly to distress screams of their own infants than do other females (control females) (Cheney and Seyfarth, 1980; Holekamp et al., 1999). Similar studies have shown that macaques also recognise kin via agonistic vocalisations (Gouzoules et al., 1986; Fischer, 2004; Fugate et al., 2008), but see Rendall et al., 1998.

However, all of these species known to use agonistic vocalisations for kin recognition have large brains and live in complex social systems (see citations above). Far less is known about small-brained or solitary species. Coalitionary behaviour benefitting kin has been observed in smaller brained, social species (lemurs: Nakamichi et al., 1997; Pereira and Kappeler, 1997; Roeder et al., 2002; but see Russell, 1983), but the role of vocalisations was not investigated. For solitary species, there are far fewer opportunities for coalitionary behaviour, however, it has still been observed (Hauver et al., 2013). The socially flexible, though generally solitary, raccoon has been observed to engage in the occasional coalitionary defence of 
food resources, though this behaviour did not appear to be driven by kin relations (Hauver et al., 2013). Here, we are following the definition of coalitions used by Gompper et al., 1997, which restricts coalitions to short-term interactions, thus excluding the relatively long-term male-male associations in some otherwise solitary species, such as mongooses (Waser et al., 1994; Schneider and Kappeler, 2014), hyenas (Wagner et al., 2007, 2008), and cheetahs (Caro and Collins, 1987; Marker, Wilkerson, 2008; Dalton et al., 2013). To our knowledge, no study has tested whether a non-group living, small-brained mammal recognises maternal kin via agonistic calls.

Here we investigate the evolution of the agonistic call in a small-brained, solitary foraging mammal, the grey mouse lemur, because it will provide an informative comparison with other, larger-brained, group-living species which are well-known for kinbased coalitions (i.e., Chapais, 1995; Silk et al., 2004; Silk, 2007; Perry et al., 2008). Grey mouse lemurs are endemic to Madagascar (Fig. 1-2). They forage alone at night, but maintain a dispersed social network, communicating with conspecifics via scentmarks and vocalisations (Müller and Thalmann, 2000; Nash, 2004). This solitary foraging pattern is believed to be ancestral to primates and the social networks are thought to have been the foundation from which more complex forms of sociality evolved in primates (Bearder, 1987; Müller and Thalmann, 2000). Thus, if kin recognition via agonistic calls is found in this species, it would suggest that such kin recognition may have enabled ancestral primates to recruit kin during agonistic encounters and that is has been the foundation for the evolution of the complex, kin-based coalitionary behaviour seen in many primates today.

Grey mouse lemurs make useful models for ancestral primates because, like the hypothesised last common ancestor of primates, they are small-bodied, nocturnal, solitary foragers that forage for fruit, insects, and gums in a fine branch niche (Cartmill, 1974; Sussman and Raven, 1978; Rasmussen, 1990; Sussman, 1991; Müller and Thalmann, 2000; Radespiel, 2000; Rendigs et al., 2003; Thorén et al., 2011: but see Soligo and Martin, 2006; Montgomery and Mundy, 2013; Andrews et al., 2016). The social system of grey mouse lemurs is strongly structured by kin relationships (Radespiel et al., 2001; Eberle and Kappeler, 2006). Males sleep alone and disperse whereas females are philopatric and remain near their natal range (Radespiel et al., 1998; Radespiel et al., 2001; Wimmer et al., 2002; Radespiel et al., 2003;
Eberle and Kappeler, 2006; Schliehe-Diecks et al., 2012). Grey mouse lemurs have a spatially structured population with predominantly male-mediated gene flow and clusters of highly related females (Wimmer et al., 2002; Radespiel et al., 2003; Fredsted et al., 2004, 2005). This has been suggested to facilitate increased cooperation and sociality among the females including matrilineal sleeping groups of female kin where the females breed cooperatively and co-nurse each other's young (Radespiel et al., 2001; Wimmer et al., 2002; Eberle and Kappeler, 2006; Lutermann et al., 2006). Because these matrilineal sleeping groups may fission (Radespiel et al., 2001), individuals may encounter matrilineal kin with whom they are unfamiliar. Kin recognition via agonistic calls could then function to

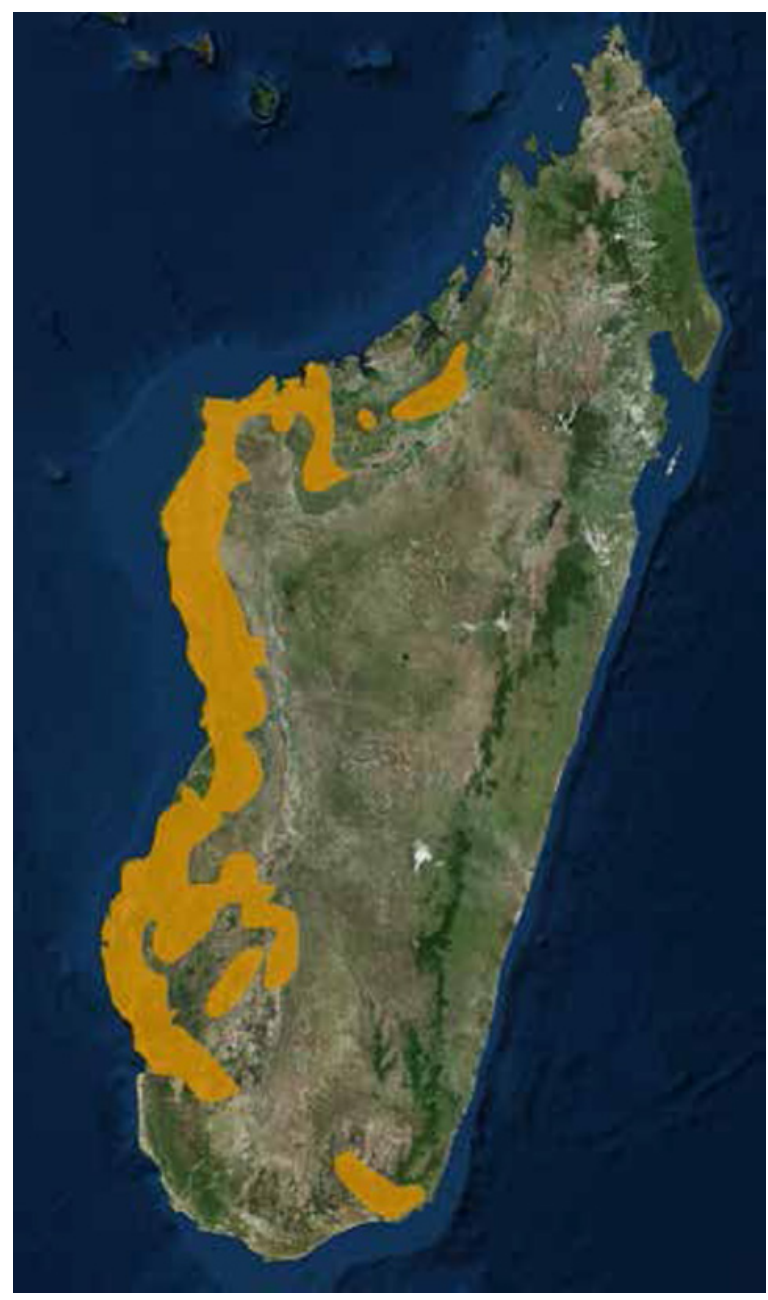

Figure 2. A map of the distribution range (orange) of the grey mouse lemur. Map taken from IUCN Red List, v. 2017-3, 201805-23. 


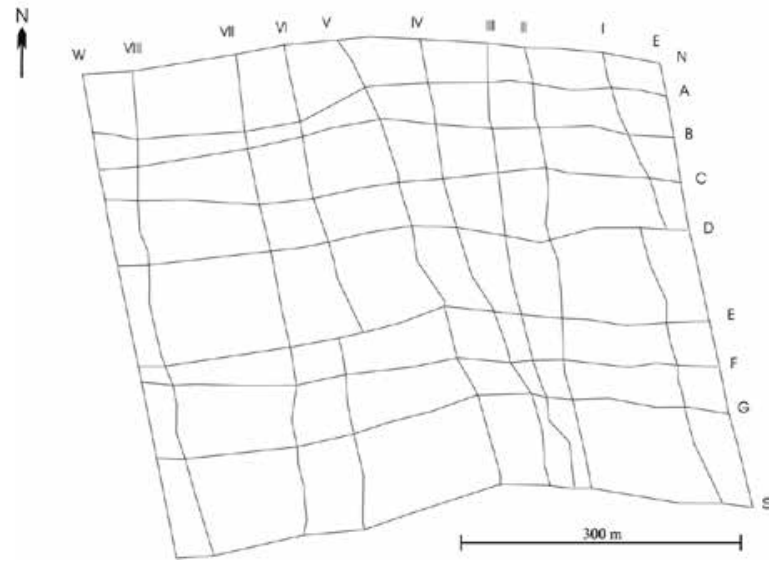

Figure 3. A map of the research grid, JBA, and the trails. The grid system of trails is labelled (top, Left-Right) W, VIII, VII, VI, V, IV, III, II, I, E and (right, top-bottom) N, A, B, C, D, E, F, $\mathrm{G}, \mathrm{S} . \mathrm{W}, \mathrm{E}, \mathrm{N}$, and $\mathrm{S}$ refer to the cardinal directions. Intersections where subjects were captured are referred to in Supplementary File 1 with both the north-south and east-west trails, i.e., AI, BII, CIII, etc. Ninety traps were used, with one being set at the start, intersection, and end points of the trails.

reduce aggression among unfamiliar matrilineal kin.

Grey mouse lemurs use a diverse set of vocalisations in a variety of contexts (i.e., mating (Buesching et al., 1998; Braune et al., 2008; Zimmermann and Radespiel, 2014), agonism (aggression/defence), disturbance situations (Leliveld et al., 2011), motherinfant contexts (Scheumann et al., 2007, 2017), and in connection with varying emotional states (Zimmermann, 2009; Altenmüller et al., 2013)). Thus, their sleeping groups provide ample opportunity to become familiar with the calls of matrilineal kin. Prior work demonstrating patrilineal kin recognition via mating calls (Kessler et al., 2012) suggests that this species possesses the cognitive capacity for kin recognition. Furthermore, anecdotal observations have documented the recruitment of nonkin via vocalisations during a predator attack. The recruited individuals mobbed the predator (a snake), which released the captured mouse lemur, suggesting that the recruitment of aid from conspecifics via vocalisations may be an important part of dispersed social networks (Eberle and Kappeler, 2008).

In this study we focus on agonistic tsak calls, which have been shown to be individually distinctive (62\% correct classification by individual (Leliveld, Scheumann et al. 2011)) and contain some signatures of matrilineal kin group (47\% correct classification by matriline, (Kessler, Radespiel et al. 2014)). The agonistic call is one of the most frequently used calls. It is a harmonic, frequency modulated call with harmonics in the audible and ultrasonic ranges. It is given at a relatively high amplitude during agonistic encounters and thus should be audible to surrounding conspecifics (Leliveld et al., 2011). Therefore, if this call facilitates kin recognition, it could function to recruit aid from kin during agonistic interactions.

We hypothesise that mouse lemurs will recognise their kin based on the proximate mechanism of familiarity. Thus we predict that subjects will react differently to vocalisations from different categories of conspecifics according to their familiarity with the caller: kin (very familiar), neighbours and cage-mates during recording (less familiar), and strangers (unfamiliar). We acknowledge that this study design does not enable us to test for direct genetic detection (Rendall, 2004) which would facilitate kin recognition in the absence of familiarity. However, because familiarity (proximate level of causation) can and does enable individuals to bias their behaviour to benefit matrilineal kin (i.e., kin selection, ultimate level of causation) (Chapais and Berman, 2004), we refer to it as kin recognition via the proximate mechanism of familiarity (Sherman, 1988).

\section{Materials and methods}

\section{Field site and trapping methodology}

This study was conducted at the Ankarafantsika National Park near the Ampijoroa forestry station $\left(16^{\circ} 19^{\prime} \mathrm{S}, 46^{\circ} 48^{\prime} \mathrm{E}\right)$ in a designated research area, Jardin Botanique A (JBA). JBA is a 30 hectare plot (approximately $600 \mathrm{~m}$ by $500 \mathrm{~m}$ ) of dry deciduous forest with a grid of trails at approximately $50 \mathrm{~m}$ intervals (Fig. 3). We conducted the fieldwork during the dry seasons in May through November of 2010 and 2011. A total of 107 Microcebus murinus were trapped in Sherman Live Traps baited with banana using established methods (Radespiel et al., 1998; Radespiel, 2000; Radespiel et al., 2001), for details see Kessler et al., 2014. The trapped lemurs were marked with subcutaneously injected microchip transponders (ID-100, Trovan Small Animal Marking System, Telinject ${ }^{\circledR}$, Römberg, Germany), and had small (1-2 $\mathrm{mm}^{2}$ ) ear biopsies taken as genetic samples. Twentyfive adult females (2010: $n=13,2011: n=15$, including 3 females collared in both years, adult $\geq 50 \mathrm{~g}$ ) were fitted with radio-collars (either a PicoPip or a Pip3 collar from BioTrack Ltd., United Kingdom, weight 
2.3-3.1 g) before release at their capture location. Radio-collared females were tracked to their daytime sleeping sites using a TR-4 receiver (Telonics, Mesa, AZ, USA). Then the collared lemurs' microchips and those of their co-sleepers were scanned with a hand-held transponder reader (Trovan Small Animal Marking System, Telinject ${ }^{\circledR}$, Römberg, Germany), thus identifying co-sleeping lemurs (data presented in (Kessler et al., 2014). We collected sleeping site data on a total of 118 days ( 65 days in 2010 and 53 days in 2011) and obtained 11-74 days of data per collared female (mean: 29 days).

\section{Recording vocalisations}

A subset of 45 lemurs was temporarily kept in cages for recording calls following the protocol described in Kessler et al., 2014. All recordings were made with a D1000X bat detector (flat frequency response: 5-235 $\mathrm{kHz}$, sampling frequency $200 \mathrm{kHz}, 16$-bit resolution, Pettersson Elektronik, Upsala, Sweden) at a distance of approximately 2-4 m. Lemurs that were caged together to elicit calls usually engaged in agonistic encounters including fighting, chasing and fleeing during which agonistic calls were recorded. These behaviours are consistent with prior research indicating that agonistic calls convey an aversion to close-contact approaches (Zimmermann, 2010). No injuries were observed in any of the lemurs. During the first night that the lemurs were caged together, the experimenter was present throughout the whole night and could separate the animals if necessary (very rare). The experimenter was always present to identify the callers when recordings were made. Though multiple cardboard cans per cage were available as sleeping sites, the lemurs typically shared a sleeping site from the first night onwards when they were caged together.

\section{Ethical statement}

Methods were approved by Madagascar National Parks (2010 permits: N102/10/MEF/SG/DGF/DCB. SAP/SCBSE, N103/10/MEF/SG/DGF/DCB.SAP/ SCBSE, 2011 permits: N101/11/MEF/SG/DGF/DCB. SAP/SCB, N102/11/MEF/SG/DGF/DCB .SAP/SCB) and the Arizona State University Institutional Animal Care and Use Committee (Protocol: 10-1077R). All animals were released at their capture locations after recording was completed (1 night - approximately 2 weeks, mean $=5$ nights).

\section{Stimuli preparation}

Playback stimuli consisted of a series of 3-5 agonistic calls repeated three times separated by approximately 3.6 seconds of background noise from the original sound file (Fig. 4). This stimulus format was chosen because it has been successfully used in other mouse lemur playback studies (Scheumann and Zimmermann, 2008; Kessler et al., 2012). In one female, the calling rate was lower than in the others, and so agonistic calls from this female were repeated only twice to produce a playback stimulus of approximately the same total length. However, in this study, the repetitions did not

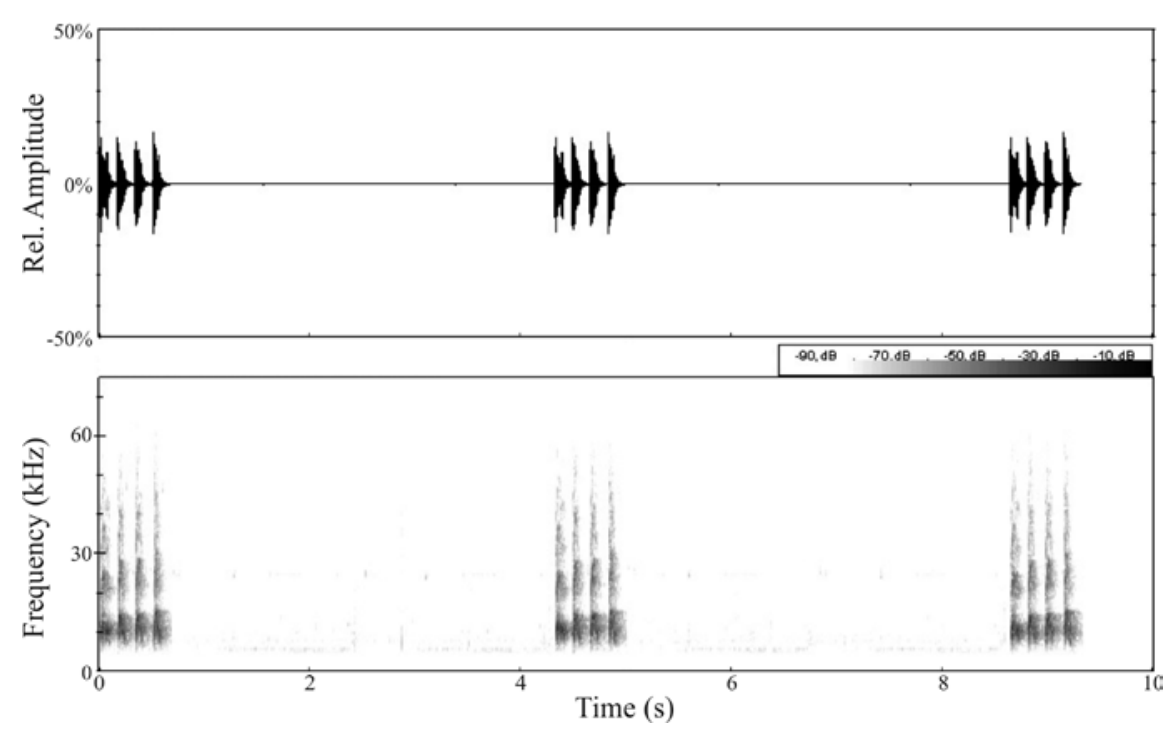

Figure 4. A spectrogram (bottom) and oscillogram (top) of a playback stimulus of the agonistic calls. Time (s) is on the $\mathrm{X}$-axis. Frequency $(\mathrm{kHz})$ and relative amplitude (\%) are on the Y-axis. Amplitude is shown on the grey scale in the spectrogram. 
alter the results and we present our analyses of the first 3 seconds after the onset of the playback (thus the first repetition only).

Playback stimuli were obtained from 22 females. The sound files were prepared in BatSound Pro 3.3.1 (Petterson Elektronik, Uppsala, Sweden), filtered with a band-pass filter $(<5 \mathrm{kHz},>90 \mathrm{kHz})$, and then uploaded to the bioacoustics lab at the Institute of Zoology, University of Veterinary Medicine where the calls were adjusted to be $75+/-1 \mathrm{~dB}$ at a distance of $1 \mathrm{~m}$ (see (Kessler et al., 2012) for details of sound pressure adjustment). However, due to technical problems, not all calls could be adjusted and 18 (30\%) of the stimuli were played at their original sound pressure level ranging from 75-80 dB, except for one stimulus which was $61 \mathrm{~dB}$ (mean pressure for all unadjusted stimuli: $76.94 \mathrm{~dB}$, standard dev. $4.22 \mathrm{~dB}$ ).

\section{Genetic analyses}

Genetic analyses were conducted at the Institute of Zoology at the University of Veterinary Medicine Hannover, Germany. Pairwise relatedness for all dyads of the 107 captured lemurs (72 males, 35 females) was calculated in Kinship 1.3.1. (Goodnight and Queller 1999) based on multilocus genotypes produced by seven nuclear microsatellites. Matrilineal relationships were confirmed by sequencing the mDNAD-loop for all captured females using the universal mammalian control region primers H16498 and L15997 (Guschanski et al., 2007). Methodological details and the genetic data are presented in full in Kessler et al. 2014.

\section{Classification of kin, neighbour, cage-mate and stranger dyads}

Dyads were classified as matrilineal kin, neighbours, cage-mates and strangers based on the following criteria (summarised in Supplementary File 1): Kin i) had a pairwise relatedness value that was significantly likely to result from a relationship of $r_{\text {maternal }}=0.5$ and $\mathrm{r}_{\text {paternal }}=0$, based on the permutations implemented in Kinship 1.3.1., ii) shared the same mitochondrial haplotype, and iii) co-slept (slept in the same sleeping site simultaneously). For three kin dyads, the cosleeping requirement was not fulfilled. Dyads 28-09 and 36-11 (first dyad), and 28-09 and 46-11 (second dyad), respectively, were not observed to co-sleep, however, all three of these females co-slept with a fourth female, 17-10. Because 36-11 and 46-11 were only captured in the second field season and 28-09 only in the first, it is likely that $28-09$ was dead in the second field season. However, if she was still alive when 36-11 and 46-11 were born, then she probably co-slept with them until her death. Females 52-11 and 113-10 (third dyad) were not observed to co-sleep, but the high relatedness between them $(r=0.36)$, having the same mitochondrial haplotype, and eating at the same feeding platform suggest that they are likely to be kin from a sleeping group that underwent a group split at some earlier time point. This phenomenon has been documented in this population (Radespiel et al., 2001). The mitochondrial haplotype could not be determined for one female, 19-10. However, she was closely related ( $\mathrm{r}=0.44)$ and co-slept with female 41-11, thus this dyad is also classified as kin.

Neighbours fed at the same feeding platform (though not necessarily simultaneously), but were not kin (pairwise relatedness was not significantly likely to result from a relationship of $r_{\text {maternal }}=0.5$ and $r_{\text {paternal }}=0$ and they did not co-sleep). Feeding at the same platform indicated that they had overlapping ranges and shared feeding sites, making it highly likely that they were familiar with each other.

Cage-mates both shared a cage during the recording and heard agonistic calls from the other lemur, but did not co-sleep in the wild, did not share a feeding platform in their home ranges, and did not have an $r$ value that was significantly likely to result from a relationship of $\mathrm{r}_{\text {maternal }}=0.5$ and $\mathrm{r}_{\text {paternal }}=0$.

Dyads were classified as strangers when they were captured more than approximately $300 \mathrm{~m}$ apart from each other. This is based upon the sum of the known ranging radius and dispersal threshold for females in this population (Radespiel et al., 2001; Radespiel et al., 2003). Prior work on this population demonstrated that females have home-ranges of 1-3 hectares which remain stable across years (Radespiel et al., 2001). Assuming a circular home-range, this can be converted to a ranging radius of $50-87 \mathrm{~m}$. Furthermore, adult females are largely philopatric and are rarely found to have dispersed further than one home-range from the natal range (median dispersal distance: $63 \mathrm{~m}$, lower quartile $23 \mathrm{~m}$, upper quartile: $119 \mathrm{~m}$ ) (Radespiel et al., 2003). Therefore, to calculate a conservative estimate we multiplied the larger home-range radius $(87 \mathrm{~m})$ by two and added the upper quartile of the dispersal distance (119 m) to obtain $293 \mathrm{~m}$ as a distance beyond which females are highly unlikely to be familiar with each other. We then rounded up to approximately 300 $\mathrm{m}$. Three of 20 stranger dyads had capture locations that were closer than $300 \mathrm{~m}$. For 06-09 and 14-09, 17- 


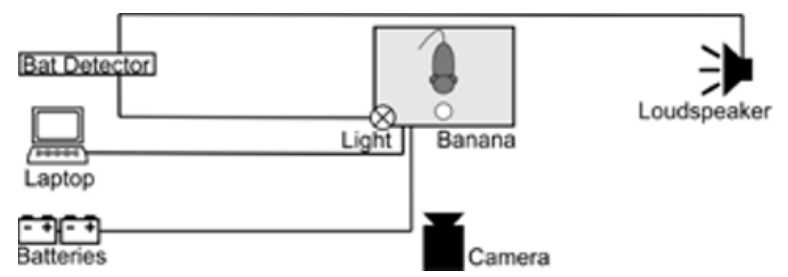

Figure 5. A top-view diagram of the set-up for the playback experiments.

10 and 10-10 this distance was very close to $300 \mathrm{~m}$ (Fig. 3 , Supplementary File 1). For one additional dyad, 4611 and 10-10, their nearest capture locations were only $\sim 200 \mathrm{~m}$ apart from each other (Fig. 3, Supplementary File 1). However, they were not captured in the same year. Given that only 38 of 69 lemurs $(55 \%)$ captured in 2011 were recaptures from prior years, the turnover rate in the population is likely to be quite high. This is in agreement with long-term studies in this population showing similar turnover rates (Radespiel et al., 2003). Therefore, we conclude that it is likely that 10-10 died before 46-11 was born and this dyad is included as a stranger dyad.

\section{Playback experiments}

Playback experiments were conducted at feeding platforms in the forest based upon the set-up used in prior work (Joly et al., 2008). (See diagram in Fig. $5)$. The platform itself consisted of a wooden shelf (29 by $40 \mathrm{~cm}$ ) on a plastic pipe approximately $1 \mathrm{~m}$ high. We placed a transponder reader (EURO ID $\mathrm{GmbH}$, Weilerswist, Germany) on the platform. The reader consisted of an AAN FK2 antenna (EURO ID, $370 \times 267 \times 49 \mathrm{~mm}$ ) connected to a EUR 410024 reader device (EURO ID) and then to a laptop (Lenovo Thinkpad T410). It was powered by two $12 \mathrm{~V}$ car batteries. Approximately $1 \mathrm{~m}$ from the feeding platform was a second platform with an ultrasonic loudspeaker with a built in amplifier (Petterson Elektronik, Uppsala, Sweden), which was connected to the ultrasonic/audible output of the D1000X bat detector. The audible output (where headphones could be attached) was connected to a set of infra-red lights which would light up when the playback started. The lights were completely in the infra-red spectrum. Infrared light is not visible to the human eye and the lemurs were not observed to look at them even when their pupils were open wide. The experiments were videotaped using the nightshot mode (which records infra red frequencies, thus displaying the infra-red lights at the onset of the playback) of a digital Sony video camera (DCR-SR210).

Calls were played while the subject ate the banana that was offered on the platform. This guaranteed that the female's head was in a standardised position at a

Table 1. Behavioural variables measured or calculated from the playback videos. D/E shows whether the variable was considered a duration or an event. Feed, Look, and Vigilant are mutually exclusive.

\begin{tabular}{lll}
\hline Measured Variables & D/E & Definition \\
\hline Onset of playback & E & $\begin{array}{l}\text { First frame in which the lights are lit up, while subject is on platform and feeding (see below and } \\
\text { text) }\end{array}$ \\
On platform & D & $\begin{array}{l}\text { Start: Onset of playback } \\
\text { End: Lemur's front feet have left the platform } \\
\text { Feed }\end{array}$ \\
Look & D & $\begin{array}{l}\text { Start: Onset of playback, thereafter when lemur bites/licks the banana } \\
\text { End: Animal has stopped biting/licking the banana }\end{array}$ \\
& Start: Lemur looks at the loudspeaker (90 to the right/left of platform, includes one frame of head \\
turn towards/away from speaker) & \\
Eigilant & D & $\begin{array}{l}\text { Start: Lemur is looking around, but not at the loudspeaker } \\
\text { End: One frame before lemur looks at loudspeaker or feeds }\end{array}$ \\
\hline Calculated Variables & D/E & Calculation \\
\hline Latency Look & D & Start of Look - Onset of playback \\
Latency Vigilant & D & Start of Vigilance - Onset of playback \\
Latency Stop Feed & D & The smaller of latency to look at loudspeaker or latency to be vigilant \\
\hline
\end{tabular}


Table 2. Component loadings of the two principal components used in the MANCOVA test. PCA reaction time and $P C A$ vigilance explained $52.0 \%$ and $20.3 \%$, respectively, of the variation in the behavioural variables.

\begin{tabular}{lll}
\hline Variable & PCA Reaction Time & PCA Vigilance \\
\hline Latency Stop Feed & 0.929 & -0.061 \\
Latency Look & 0.823 & 0.452 \\
Feed & 0.815 & 0.032 \\
Latency Vigilant & 0.783 & -0.460 \\
Vigilant & -0.283 & 0.748 \\
Look & -0.474 & -0.486 \\
\hline
\end{tabular}

standardised distance $(1 \mathrm{~m})$ from the loudspeaker. Call types (kin, neighbour, cage-mate, and stranger) were played in a pseudo-randomised order with a minimum of 5 minutes between two stimuli. No subject heard all of its stimuli on the same night.

A frame-by-frame analysis was conducted in Observer XT 10 (Noldus Information Technology) by an observer who was blind to which stimulus the subject heard (because the calls are high frequency with harmonics in the ultrasonic range, it is not possible to distinguish the caller while listening to the videos (recorded with a camcorder that is not specialised for high frequency recording). We analysed $3 \mathrm{~s}$ after the onset of the playback (marked by the infra-red lights), measuring seven behavioural variables (detailed ethogram in Table 1, diagram of experimental set-up in Fig. 5). Because the lemurs left the platform in only 4 of 57 trials, we discarded the variable duration on the platform due to a lack of variation.

\section{Statistics}

We tested for intra-observer reliability by re-coding $22 \%$ of the videos (using our original analysis period of $11.96 \mathrm{~s}$ which encompassed all three call repetitions) and testing for differences between the two sets of data with a Wilcoxon Matched Pairs test. Though two behavioural variables were significantly different after a Bonferroni correction (Wilcoxon Matched Pairs Test, $\mathrm{Z}_{\text {latency vigiant }}=-3.072$ and $\mathrm{Z}_{\text {latency stop feed }}=-2.869, \mathrm{~N}=24$, $\mathrm{p}<0.05$ ), they were retained in the analyses for data exploration because the mean differences between the two codings were small (latency vigilant $=1.4 \mathrm{~s}$ and latency stop feed $=0.1 \mathrm{~s}$ ).

We tested whether sound pressure level represented a significant confound by comparing the behavioural variables (feed, look, vigilant, latency look, latency vigilant, latency stop feed) measured from trials where the sound pressure level was adjusted to $75+/$ $1 \mathrm{~dB}$ to those trials where the sound pressure level was not adjusted using a Mann Whitney U test. (As in the intra-observer reliability test, we incorporated our original analysis period of $11.96 \mathrm{~s}$ which encompassed all three call repetitions). Because, aside from one trial with a sound pressure level of $61 \mathrm{~dB}$, all unadjusted stimuli were $75 \mathrm{~dB}$ or louder, we expected reactions to be stronger to the unadjusted stimuli than to the adjusted stimuli. Therefore we excluded the trial with $61 \mathrm{~dB}$ from this test. Because none of the tests were significant after a Bonferroni correction (Mann Whitney $\mathrm{U}$ test, $\mathrm{U} \geq 225, \mathrm{~N}_{\text {adjusted }}=39, \mathrm{~N}_{\text {unadjusted }}=17$, test-wide alpha $>0.05$ ), we retained all trials in the analyses.

In order to investigate whether the variation in responses could be driven primarily by the animals' hunger, we compared reactions of individuals who returned multiple times per night reasoning that they should be hungriest during their earlier visits and therefore less interested in the playbacks. We found that reactions did not differ according to whether it was an earlier or later visit for any of the behavioural variables (Wilcoxon Matched Pairs Tests, $\mathrm{Z} \geq-1.778$, $\mathrm{N}=13$ pairs, Bonferroni corrected test-wide alpha $>$ 0.05). Furthermore, because most subjects heard all of their stimuli within a couple weeks (after which the feeding platform was moved to a different part of the forest), we do not expect the month in which the experiments were conducted to have created motivational differences within subjects.

We ran a MANCOVA testing for differences in the responses to the different call types (kin, neighbour, cage-mate, and stranger). We tested for normality using the Kolmogorov-Smirnov test (Supplementary File 2). Because some violations are present, we interpret the MANCOVA's Pillai-Bartlett trace statistic, which is relatively robust to violations of assumptions (Field, 2009). We reduced our dataset of six correlated behavioural variables to two uncorrelated variables using principal components analysis. We conducted a principal components analysis (no rotation) on the correlation matrix and extracted all components with eigenvalues greater than 1 (Kaiser's criterion (Field, 2009)). We named the two principal components $P C A$ reaction time and $P C A$ vigilance based on the original variables which loaded most highly (Table 2) onto them. Latency stop feed, latency look, feed, and latency 
vigilant loaded highly on the first component $(>0.7)$, indicating that it incorporates variation in how quickly subjects reacted to the playback by stopping feeding and then looking at the speaker or becoming vigilant. Vigilance loaded highly on the second component $(>0.7)$. Look loaded negatively on PCA vigilant, reflecting that the categories of vigilant and look were mutually exclusive. Following published methods (Field, 2009), we conducted a MANCOVA using $P C A$ reaction time and $P C A$ vigilant as dependent variables and call type as a fixed factor. Because we expected the subjects to habituate to the experimental set-up, and this could influence the reactions, we included order (the trial number for that individual, range: 1-13) as a covariate. Trial numbers were numbered within individuals, thus this enabled us to account for habituation effects and subject effects. All statistical tests were run in SPSS 2024 (IBM Corp.). Alpha was set at 0.05 .

\section{Results}

\section{Genetic relatedness}

Median pairwise relatedness for all dyads in the population was $r=-0.02(n=107$ individuals, $\min =-0.38$, $\max =0.91$ ). Median pairwise relatedness within kin dyads was $\mathrm{r}=0.44(\mathrm{n}=19$ dyads, $\min =0.17, \max =0.62)$, whereas median relatedness was $\mathrm{r}=0.01$ between neighbour dyads $(\mathrm{n}=7$ dyads, $\min =-0.05, \max =0.11)$, $\mathrm{r}=-0.02$ between cage-mate dyads $(\mathrm{n}=11$ dyads, $\min =-$ 0.12 , $\max =0.16$ ), and $\mathrm{r}=-0.04$ between stranger dyads $(\mathrm{n}=20$ dyads, $\min =-0.28, \max =0.19) \quad$ (Supplementary File 1). We found seven mitochondrial haplotypes in the females of this population (Kessler, Radespiel et al. 2014). Females included in this study belonged to H1, H3, H4, H5, H6, and H7 (Supplementary File 1). See Kessler et al., 2014 for a haplotype network.

Differences in reactions to calls from kin, cage-mates, neighbours, and strangers

Supplementary File 3 provides descriptive statistics including the means and standard deviations for the variables across the different call types 3 seconds after the playback.

Overall, PCA reaction time and PCA vigilance explained $52.0 \%$ and $20.3 \%$, respectively, of the variation in the original behavioural variables (Table 2). Using the Pillai-Bartlett trace, there was no effect of call type on subjects' responses to playbacks $(\mathrm{V}=0.121$,
$\mathrm{F}(6,104)=1.120, \mathrm{p}=0.356)$ when controlling for order effects $(\mathrm{V}=0.136, \mathrm{~F}(2,51)=4.004, \mathrm{p}=0.024)$. Fig. 6 shows that the mean time subjects engaged in the behavioural categories of feed, latency stop feed, feed, latency vigilant, vigilant, latency look, and look were very similar after hearing the different types of calls.

\section{Discussion}

\section{Evolutionary significance of the findings}

Our results show that the subjects' reactions to the kinship and familiarity-based playback stimuli were not significantly different, suggesting that the smallbrained, solitary foraging grey mouse lemurs do not appear to use agonistic calls to monitor conflicts involving their kin (Fig. 6). This is a stark contrast to the large-brained, socially complex monkeys and hyenas (Cheney and Seyfarth, 1980; 1999; Holekamp et al., 1999)) which engage in frequent kin-biased, coalitionary behaviour.

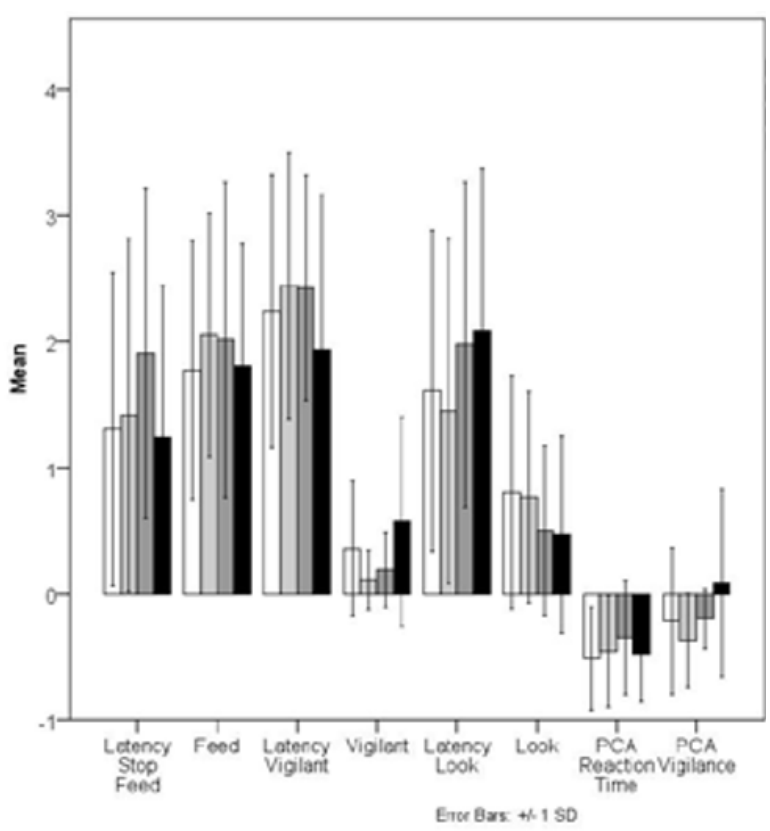

Figure 6. Graphs of latency stop feed, feed, latency vigilant, vigilant, latency look, look, PCA reaction time, and PCA vigilant at 3 seconds after the onset of the playback. The Y-axis is the mean time (s) that playback listeners spent in each behaviour or (for $P C A$ reaction time and $P C A$ vigilant) the mean component score. 
This difference has implications for our understanding of the evolution of coalitionary behaviour and social complexity. It suggests that dispersed social networks, believed to be the ancestral condition in primates (Bearder, 1987; Müller and Thalmann, 2000), do not select for the use of agonistic calls to recruit aid from kin. Instead, it appears that greater social complexity is necessary. Our findings imply that ancestral, solitary foraging primates living in dispersed social networks similar to those of the extant grey mouse lemur did not recognise kin via agonistic calls or use these vocalisations to recruit aid from kin. Furthermore, kin recognition via agonistic calls may have either evolved independently in hyenas and monkeys, possibly in connection with the evolution of frequent kin-biased coalitionary behaviour (Cheney and Seyfarth, 1980; 1999; Holekamp et al., 1999)). Interestingly, this scenario would support the social complexity hypothesis, which argues that increases in social complexity can drive increases in communicative complexity (Freeberg et al., 2012). The tight link between frequent coalitionary behaviour and the use of agonistic calls to recognise kin in two phylogenetically distant taxa, monkeys and hyenas (Cheney and Seyfarth, 1980; 1999; Holekamp et al., 1999), would imply that the social complexity of coalitionary behaviour drove the corresponding vocal complexity, and not the reverse (Freeberg et al., 2012). An additional, but equally parsimonious explanation would be that kin recognition via agonistic calls was present in ancestral primates but was lost in mouse lemurs due to a lack of selective pressure maintaining it.

\section{Cognitive implications}

The lack of significant differences in the behavioural responses to the playbacks raises two possibilities. The first is that the subjects recognised their kin, neighbours, cage-mates, and strangers, but did not react differently to the different call types using the variables we measured. The second is that the subjects did not recognise the different categories of callers and so did not react differently. It is difficult for us to determine which of the two explanations is correct.

It is possible that the food that was offered as bait, to attract the animals to the platform, was so valuable that the females concentrated on eating and were not motivated to differentiate between the callers, even if they recognised who was calling. This explanation might account for the somewhat surprising finding that mouse lemurs did not respond differently to strangers than to familiar individuals. Even though mouse lemurs have highly overlapping ranges (Radespiel, 2000), we expected them to respond differently to neighbours (with whom they are likely familiar) and strangers.

The alternative explanation is that perhaps the lemurs did not respond differently to kin and nonkin, because the calls do not contain sufficient kin-specific acoustic signatures. Previous studies showed that agonistic calls can only be classified by kin group at a rate of $47 \%$ (Kessler et al., 2014) and by individual at a rate of $62 \%$ (Leliveld et al., 2011). It may be that kin and individual signatures are simply not pronounced enough in agonistic calls for listeners to perceive them and thus use them to facilitate recognition of kin or individuals. Prior work showed that female mouse lemurs discriminated paternal kin from nonkin based on mating call signatures with an $79 \%$ classification rate, but not based on alarm calls with a $45 \%$ classification rate (Kessler et al., 2012). Similar differences in reactions to acoustic signatures have been found across call types in other species, e.g., baboons (Rendall et al., 2009). However, such classification rates should be viewed conservatively, as there are likely to be discrepancies between what the animals perceive as biologically relevant and what we as researchers consider to be statistically significant (Fugate et al., 2008).

Since we have only tested one call type, our results do not indicate that mouse lemurs are unable to recognise maternal kin via other vocalisations. Other researchers have argued that the noisy quality typical of agonistic calls makes them ill suited to displaying acoustic signatures (Rendall et al., 1996, 1998; Owren and Rendall, 2001). While formants have been proposed to be highly important for individual signatures among larger species, i.e., anthropoid primates (Fitch, 1997; Owren and Rendall, 2001; Rendall, 2003; Rendall et al., 2005), formants are believed to be less significant among smaller species that give high frequency/ultrasonic calls, (Ehret, 2006; Leliveld et al., 2011). Prior research compared the strength of acoustic signatures across four call types in mouse lemurs and found that harmonic, long distance calls were more individually distinctive than the noisier (though still harmonic), short distance agonistic calls (Leliveld et al., 2011). Therefore, future work should investigate whether harmonic, long distance call types (e.g., gathering calls) are used for kin recognition in 
grey mouse lemurs. The closely related species, $M$. ravelobensis (Zimmermann et al., 1998), has been shown to use gathering calls with group-specific signatures for meeting at sleeping sites (Braune et al., 2005), implying that they can probably recognise group members by these calls. Further work should be done investigating other species, including solitary species, solitary foragers, and social species, to determine whether kin recognition via agonistic calls has evolved only in species with frequent kin-biased coalitionary behaviour.

Regardless of the underlying cognitive process, mouse lemurs showed a very different reaction to agonistic calls of kin than did large-brained, socially complex monkeys and hyenas. In contrast to the monkeys and hyenas (Cheney and Seyfarth 1980; 1999; Holekamp et al., 1999), the mouse lemurs showed no sign of heightened attention to the agonistic calls of kin (Fig. 6). Our findings are consistent with the lack of reports on widespread coalitionary behaviour in mouse lemurs and suggest that in contrast to large-brained, socially complex species (Cheney and Seyfarth 1980; 1999; Holekamp et al., 1999), the small-brained, solitary foraging mouse lemur does not appear to use agonistic vocalisations to monitor agonistic interactions involving kin, or perhaps, any conspecifics engaged in conflicts with other conspecifics.

\section{Conclusions}

Grey mouse lemurs did not react differently to any of the call types. This suggests that the small-brained, solitary foraging mouse lemurs do not use agonistic calls to monitor agonistic interactions involving their kin. This is in stark contrast to large-brained, socially complex monkeys and hyenas which engage in frequent kinbiased, coalitionary behaviour (Cheney and Seyfarth 1980; 1999; Holekampetal., 1999). Thus, kin recognition via agonistic calls appears to have either 1) evolved later during primate evolution and independently in hyenas, in connection with greater social complexity and frequent coalitionary behaviour or 2) been lost in the lineage leading to mouse lemurs. The tight linkage between the evolution of frequent coalitionary behaviour and the use of agonistic calls to monitor conflicts involving kin may support the social complexity hypothesis (Freeberg et al., 2012). It suggests that the use of agonistic calls to monitor interactions involving kin may not greatly predate and thus facilitate the evolution of widespread kin-based coalitions; instead, coalitionary behaviour may have been an important driver for the evolution of greater communicative complexity involving the agonistic calls.

\section{Acknowledgements}

We thank the Malagasy government, Ministère de 1'Environnement, de l'Ecologie, et des Forêts, and Madagascar National Parks (MNP) for their permission to work in the Ankarafantsika National Park and for their support during our fieldwork. We are grateful to Solofonirina Rasoloharijaona, Blanchard Randrianambinina and the Faculté des Sciences, Université de Mahajanga for valuable training and logistical support in the field, Jhonny Kennedy and Jean de la Croix for guide services, Hella Breitrueck for assistance in the genetics lab, Marine Joly for advice on Observer, Soenke von den Berg and Philipp Hohenbrink for technical support, and three anonymous reviewers for valuable, critical, and constructive comments. Funding was provided by an NSF Dissertation Improvement Grant (\#0961779), PEO Scholar Award, the Animal Behaviour Society, Lewis and Clark Fund of the American Philosophical Society, German Academic Exchange Service (\#A/09/81743), American Society of Primatologists, Sigma Xi (National Chapter, grant \#G2009101504), Sigma Xi (Arizona State University chapter), Arizona State University Graduate and Professional Student Association, Arizona State University School of Human Evolution and Social Change, an Arizona State University Graduate College Dissertation Writing Fellowship, a Marie Sklodowska-Curie individual Fellowship (\#703611), and the Institute of Zoology, Division of Behaviour and Evolution, University of Veterinary Medicine Hannover.

\section{References}

Altenmüller E, Schmidt S, Zimmermann E, Eds. 2013. The Evolution of Emotional Communication: From Sounds in Nonhuman Mammals to Speech and Music in Man. Oxford, Oxford University Press.

Andrews C, Rambeloarivony H, Génin F, Masters J. 2016. Why cheirogaleids are bad models for primate ancestors: A phylogenetic reconstruction. Dwarf and Mouse Lemurs of Madagascar: Biology, Behaviour and Conservation Biogeography of the Cheirogaleidae. Lehman SM, Radespiel U and Zimmermann E. Cambridge, Cambridge University Press.

Balcombe JP. 1990. Vocal recognition of pups by mother Mexican free-tailed bats, Tadarida brasiliensis mexicana. Animal Behaviour 39: 960-966.

Bearder SK. 1987. Lorises, bushbabies, and tarsiers: diverse societies in solitary foragers. Primate Societies. Smuts BB, Cheney DL, Seyfarth RM, Wrangham R and Struhsaker TT. Chicago, University of Chicago Press: 11-24.

Braune P, Schmidt S, Zimmermann E. 2005. Spacing and group coordination in a nocturnal primate, the golden brown mouse lemur (Microcebus ravelobensis): the role of olfactory and 
acoustic signals. Behavioural Ecology and Sociobiology 58: 587-596.

Braune P, Schmidt S,Zimmermann E. 2008. Acoustic divergence in the communication of cryptic species of nocturnal primates (Microcebus ssp.). BMC Biology 6:19.

Briefer E, McElligott AG. 2011. Mutual mother-offspring vocal recognition in an ungulate hider species (Capra hircus). Animal Cognition 14: 585-598.

Briefer EF, de la Torre MP, McElligott AG. 2012. Mother goats do not forget their kids' calls. Proceedings of the Royal Society B-Biological Sciences 279: 3749-3755.

Buesching CD, Heistermann M, Hodges JK, Zimmermann E. 1998. Multimodal oestrus advertisement in a small nocturnal prosimian, Microcebus murinus. Folia Primatologica 69: 295-308.

Caro TM, Collins DA. 1987. Male cheetah social organization and territoriality. Ethology 74: 52-64.

Cartmill M. 1974. Rethinking primate origins. Science 184: 436-443.

Chapais B. 1995. Alliances as a means of competition in primates: Evolutionary, developmental, and cognitive aspects. Yearbook of Physical Anthropology, 1995 38: 115136.

Chapais B, Berman CM, Eds. 2004. Kinship and Behaviour in Primates. New York, Oxford University Press.

Cheney DL, Seyfarth RM. 1980. Vocal recognition in freeranging vervet monkeys. Animal Behaviour 28: 362-367.

Cheney DL, Seyfarth RM. 1999. Recognition of other individuals' social relationships by female baboons. Animal Behaviour 58: 67-75.

Dalton DL, Charruau P, Boast L, Kotze A. 2013. Social and genetic population structure of free-ranging cheetah in Botswana: implications for conservation. European Journal of Wildlife Research 59: 281-285.

de Waal F, Tyack PL, Eds. 2003. Animal Social Complexity: Intelligence, Culture, and Individualized Societies. Cambridge, Harvard University Press.

Dunbar R. 1998. The social brain hypothesis. Evolutionary Anthropology 6: 178-190.

Dunbar R. 2003. Evolution of the social brain. Science 302: 1160-1161.

Eberle M, Kappeler PM. 2006. Family insurance: kin selection and cooperative breeding in a solitary primate (Microcebus murinus). Behavioural Ecology and Sociobiology 60: 582588.

Eberle M, Kappeler PM. 2008. Mutualism, reciprocity, or kin selection? Cooperative rescue of a conspecific from a boa in a nocturnal solitary forager the gray mouse lemur. American Journal of Primatology 70: 410-414.

Ehret G. 2006. Common rules of communication and sound perception. Behaviour and Neurodynamics for Auditory Communication. Kanwal J and Ehret G. Cambridge, Cambridge University Press: 85-114.

Field A. 2009. Discovering statistics using SPSS. London, Sage.

Fischer J. 2004. Emergence of individual recognition in young macaques. Animal Behaviour 67: 655-661.

Fitch WT. 1997. Vocal tract length and formant frequency dispersion correlate with body size in rhesus macaques. Journal of the Acoustical Society of America 102: 12131222.

Fredsted T, Pertoldi C, Olesen JM, Eberle M, Kappeler PM.
2004. Microgeographic heterogeneity in spatial distribution and mtDNA variability of gray mouse lemurs (Microcebus murinus, Primates : Cheirogaleidae). Behavioural Ecology and Sociobiology 56: 393-403.

Fredsted T, Pertoldi C, Schierup MH, Kappeler PM. 2005. Microsatellite analyses reveal fine-scale genetic structure in grey mouse lemurs (Microcebus murinus). Molecular Ecology 14: 2363-2372.

Freeberg TM, Dunbar RIM, Ord TJ. 2012. Social complexity as a proximate and ultimate factor in communicative complexity Philosophical Transactions of the Royal Society B-Biological Sciences 367: 1785-1801.

Fugate JMB, Gouzoules H, Nygaard LC. 2008. Recognition of rhesus macaque (Macaca mulatta) noisy screams: Evidence from conspecifics and human listeners. American Journal of Primatology 70: 594-604.

Gilby IC, Brent LJN, Wroblewski EE, Rudicell RS, Hahn BH, Goodall J, Pusey AE. 2013. Fitness benefits of coalitionary aggression in male chimpanzees. Behavioural Ecology and Sociobiology 67: 373-381.

Gompper ME, Gittleman JL, Wayne RK. 1997. Genetic relatedness, coalitions and social behaviour of white-nosed coatis, Nasua narica. Animal Behaviour 53: 781-797.

Goodnight KF, Queller DC. 1999. Computer software for performing likelihood tests of pedigree relationship using genetic markers. Molecular Ecology 8: 1231-1234.

Gouzoules S, Gouzoules H,MarlerP.1986. Vocal communication: a vehicle for the study of social relationships. The Cayo Santiago Macaques: History, Behaviour, and Biology. Rawlins RG and Kessler MJ. Albany, State University of New York Press: 111-129.

Gros-Louis J, Perry S, Manson JH. 2003. Violent coalitionary attacks and intraspecific killing in wild white-faced capuchin monkeys (Cebus capucinus). Primates 44: 341-346.

Guschanski K, Olivieri G, Funk SM, Radespiel U. 2007. MtDNA reveals strong genetic differentiation among geographically isolated populations of the golden brown mouse lemur, Microcebus ravelobensis. Conservation Genetics 8: 809-821.

Hamilton WD. 1964. The genetical evolution of social behaviour. I and II. Journal of Theoretical Biology 7: 1-52.

Hauver S, Hirsch BT, Prange S, Dubach J, Gehrt SD. 2013. Age, but not sex or genetic relatedness, shapes raccoon dominance patterns. Ethology 119: 769-778.

Holekamp KE, Boydston EE, Szykman M, Graham I, Nutt KJ, Birch S, Piskiel A, Singh M. 1999. Vocal recognition in the spotted hyaena and its possible implications regarding the evolution of intelligence. Animal Behaviour 58: 383-395.

Insley SJ, Phillips AV, Charrier I. 2003. A review of social recognition in pinnipeds. Aquatic Mammals 29: 181-201.

Joly M, Scheumann M, Zimmermann E. 2008. Wild mouse lemurs revisit artificial feeding platforms: Implications for field experiments on sensory and cognitive abilities in small primates. American Journal of Primatology 70: 892-896.

Kessler SE, Radespiel U, Hasiniaina A, Leliveld L, Nash LT, Zimmermann E. 2014. Modeling the origins of mammalian sociality: Moderate evidence for matrilineal signatures in mouse lemur vocalisations. Frontiers in Zoology 11: 14.

Kessler SE, Scheumann M, Nash LT, Zimmermann E. 2012. Paternal kin recognition in the high frequency / ultrasonic range in a solitary foraging mammal. BMC Ecology 12: 26.

Knoernschild M, Von Helversen O. 2008. Nonmutual vocal 
mother-pup recognition in the greater sac-winged bat Animal Behaviour 76: 1001-1009.

Leliveld LMC, Scheumann M, Zimmermann E. 2011. Acoustic correlates of individuality in the vocal repertoire of a nocturnal primate (Microcebus murinus). Journal of the Acoustical Society of America 129: 2278-2288.

Lutermann H, Schmelting B, Radespiel U, Ehresmann P, Zimmermann E. 2006. The role of survival for the evolution of female philopatry in a solitary forager, the grey mouse lemur (Microcebus murinus). Proceedings of the Royal Society B-Biological Sciences 273: 2527-2533.

Marker LL, Wilkerson AJP, Sarno RJ, Martenson J, Breitenmoser-Wuersten C, O'Brien SJ, Johnson WE. 2008. Molecular genetic insights on cheetah (Acinonyx jubatus) ecology and conservation in Namibia. Journal of Heredity 99: 2-13.

McComb K, Moss C, Sayialel S, Baker L. 2000. Unusually extensive networks of vocal recognition in African elephants. Animal Behaviour 59: 1103-1109.

McComb K, Reby D, Baker L, Moss C, Sayialel S. 2003. Longdistance communication of acoustic cues to social identity in African elephants. Animal Behaviour 65: 317-329.

Montgomery SH, Mundy N. 2013. Parallel espidoes of phyletic dwarfism in callitrichid and cheirogaleid primates. Journal of Evolutionary Biology 26: 810-819.

Müller AE, Thalmann U. 2000. Origin and evolution of primate social organisation: A reconstruction. Biological Review 75: 405-435.

Nakamichi M, Rakototiana MLO, Koyama N. 1997. Effects of spatial proximity and alliances on dominance relations among female ring-tailed lemurs (Lemur catta) at Berenty Reserve, Madagascar. Primates 38: 331-340.

Nash LT. 2004. Kinship and behaviour among nongregarious nocturnal prosimians: What do we really know? Kinship and Behaviour in Primates. Chapais B and Berman CM. New York, Oxford University Press: 200-222.

Nunn CL. 2000. Maternal recognition of infant calls in ringtailed lemurs. Folia Primatologica 71: 142-146.

Owren MJ, Rendall D. 2001. Sound on the rebound: Bringing form and function back to the forefront in understanding nonhuman primate vocal signaling. Evolutionary Anthropology 10: 58-71.

Pereira ME, Kappeler PM. 1997. Divergent systems of agonistic behaviour in lemurid primates. Behaviour 134: 225-274.

Perry S, Manson JH, Muniz L, Gros-Louis J, Vigilant L. 2008. Kin-biased social behaviour in wild adult female white-faced capuchins, Cebus capucinus. Animal Behaviour 76: 187-199.

Radespiel U. 2000. Sociality in the gray mouse lemur (Microcebus murinus) in northwestern Madagascar. American Journal of Primatology 51: 21-40.

Radespiel U, Cepok S, Zietemann V, Zimmermann E. 1998. Sex-specific usage patterns of sleeping sites in grey mouse lemurs (Microcebus murinus) in northwestern Madagascar. American Journal of Primatology 46: 77-84.

Radespiel U, Lutermann H, Schmelting B, Bruford MW, Zimmermann E. 2003. Patterns and dynamics of sex-biased dispersal in a nocturnal primate, the grey mouse lemur, Microcebus murinus. Animal Behaviour 65: 709-719.

Radespiel U, Sarikaya Z, Zimmermann E, Bruford MW. 2001. Sociogenetic structure in a free-living nocturnal primate population: sex-specific differences in the grey mouse lemur (Microcebus murinus). Behavioural Ecology and Sociobiology 50: 493-502.

Rasmussen DT. 1990. Primate origins - Lessons from a neotropical marsupial. American Journal of Primatology 22: 263-277.

Rendall D. 2003. Acoustic correlates of caller identity and affect intensity in the vowel-like grunt vocalisations of baboons. Journal of the Acoustical Society of America 113: 33903402.

Rendall D. 2004. Recognizing kin: mechanisms, media, minds, modules, and muddles. Kinship and Behaviour in Primates. Chapais B and Berman CM. New York, Oxford University Press: 295-316.

Rendall D, Kollias S, Ney C. 2005. Pitch $\left(\mathrm{F}_{0}\right)$ and formant profiles of human vowels and vowel-like baboon grunts: The role of vocalizer body size and voice-acoustic allometry. Journal of the Acoustical Society of America 117: 944-955.

Rendall D, Notman H, Owren MJ. 2009. Asymmetries in the individual distinctiveness and maternal recognition of infant contact calls and distress screams in baboons. Journal of the Acoustical Society of America 125: 1792-1805.

Rendall D, Owren MJ, Rodman PS. 1998. The role of vocal tract filtering in identity cueing in rhesus monkey (Macaca mulatta) vocalisations. Journal of the Acoustical Society of America 103: 602-614.

Rendall D, Rodman PS, Emond RE. 1996. Vocal recognition of individuals and kin in free-ranging rhesus monkeys. Animal Behaviour 51: 1007-1015.

Rendigs A, Radespiel U, Wrogemann D, Zimmermann E. 2003. Relationship between microhabitat structure and distribution of mouse lemurs (Microcebus spp.) in Northwestern Madagascar. International Journal of Primatology 24: 47-64.

Roeder JJ, Duval L, Gosset D. 2002. Aggressive and neutral interventions in conflicts in captive groups of brown lemurs (Eulemur fulvus fulvus). American Journal of Physical Anthropology 118: 253-258.

Russell JK. 1983. Altruism in coati bands: Nepotism or reciprocity? Social Behaviour of Female Vertebrates. Wasser SK. New York, New York Academic Press: 263-290.

Scheumann M, Linn S, Zimmermann E. 2017. Vocal greeting during mother-infant reunions in a nocturnal primate, the gray mouse lemur (Microcebus murinus). Scientific Reports 7: 10321

Scheumann M, Zimmermann E. 2008. Sex-specific asymmetries in communication sound perception are not related to hand preference in an early primate. BMC Biology 6 .

Scheumann M, Zimmermann E, Deichsel G. 2007. Contextspecific calls signal infants' needs in a strepsirrhine primate, the gray mouse lemur (Microcebus murinus). Developmental Psychobiology 49: 708-718.

Schliehe-Diecks S, Eberle M, Kappeler PM. 2012. Walk the line-dispersal movements of gray mouse lemurs (Microcebus murinus). Behavioural Ecology and Sociobiology 66: 11751185 .

Schneider TC, Kappeler PM. 2014. Social systems and lifehistory characteristics of mongooses. Biological Reviews 89: 173-198.

Seyfarth RM, Cheney DL. 2003. The structure of social knowledge in monkeys. Animal Social Complexity. de Waal F and Tysck PL. Cambridge, MA, Harvard University Press: 207-229. 
Sherman PW. 1988. Levels of analysis. Animal Behaviour 36: 616-619.

Silk JB. 2002. Kin selection in primate groups. International Journal of Primatology 23: 849-875.

Silk JB. 2007. Social components of fitness in primate groups. Science 317: 1347-1351.

Silk JB, Alberts SC, Altmann J. 2004. Patterns of coalition formation by adult female baboons in Amboseli, Kenya. Animal Behaviour 67: 573-582.

Smith K, Alberts SC, Altmann J. 2003. Wild female baboons bias their social behaviour towards paternal half-sisters. Proceedings of the Royal Society of London Series B-Biological Sciences 270: 503-510.

Soligo C, Martin RD. 2006. Adaptive origins of primates revisited. Journal of Human Evolution 50: 414-430.

Sussman RW. 1991. Primate origins and the evolution of angiosperms. American Journal of Primatology 23: 209-223.

Sussman RW, Raven PH. 1978. Pollination by lemurs and marsupials - Archaic coevolutionary system. Science 200: 731-736

Talebi M, Belatrão-Mendes R, Lee P. 2009. Intra-community coalitionary lethal attack of an adult male southern muriqui (Brachyteles arachnoides). American Journal of Primatology 71: 860-867.

Thorén S, Quietzsch F, Schwochow D, Sehen L, Meusel C, Meares K, Radespiel U. 2011. Seasonal changes in feeding ecology and activity patterns of two sympatric mouse lemur species, the gray mouse lemur (Microcebus murinus) and the golden-brown mouse lemur (M. ravelobensis), in northwestern Madagascar. International Journal of Primatology 32: 566-586.

Wagner AP, Creel S, Frank LG, Kalinowski ST. 2007. Patterns of relatedness and parentage in an asocial, polyandrous striped hyena population. Molecular Ecology 16: 4356-4369.

Wagner AP, Frank LG, Creel S. 2008. Spatial grouping in behaviourally solitary striped hyaenas, Hyaena hyaena. Animal Behaviour 75: 1131-1142.

Waser PM, Keane B, Creel S, Elliott LF, Minchella DJ. 1994. Possible male coalitions in a solitary mongoose. Animal Behaviour 47: 289-294.

Widdig A, Streich WJ, Nurnberg P, Croucher PJP, Bercovitch FB, Krawczak M. 2006. Paternal kin bias in the agonistic interventions of adult female rhesus macaques (Macaca mulatta). Behavioural Ecology and Sociobiology 61: 205-214.

Wimmer B, Tautz D, Kappeler PM. 2002. The genetic population structure of the gray mouse lemur (Microcebus murinus), a basal primate from Madagascar. Behavioural Ecology and Sociobiology 52: 166-175.

Wittig RM, Crockford C, Seyfarth RM, Cheney DL. 2007. Vocal alliances in Chacma baboons (Papio hamadryas ursinus). Behavioural Ecology and Sociobiology 61: 899-909.

Zimmermann E. 2009. Vocal expression of emotion in a nocturnal prosimian primate group, mouse lemurs. Handbook of Mammalian Vocalisations: An Integrative Neuroscience Approach. Brudzynski SM. Oxford, Academic Press: 215-225.

Zimmermann E. 2010. Vocal expression of emotion in a nocturnal prosimian primate group, mouse lemurs. Handbook of Mammalian Vocalization: An Integrative Neuroscience Approach. Brudzynski SM. Oxford, Academic Press: 215-225.
Zimmermann E, Cepok S, Rakotoarison N, Zietemann V, Radespiel U. 1998. Sympatric mouse lemurs in northwest Madagascar: A new rufous mouse lemur species (Microcebus ravelobensis). Folia Primatologica 69: 106-114.

Zimmermann E, Radespiel U. 2014. Species concepts, diversity, and evolution in primates: Lessons to be learned from mouse lemurs. Evolutionary Anthropology 23: 11-14.

Received: 22 May 2018

Revised and accepted: 26 October 2018

Published online: 30 November 2018

Editor: V. Nijman

\section{Online supplementary information}

Supplementary File 1

Supplementary File 2

Supplementary File 3 